\title{
Distance Education and Student Satisfaction Regarding the Pedagogical Support Services Provided in Virtual Teaching-learning Environments
}

\author{
https://doi.org/10.3991/ijet.v16i20.24559 \\ Omar Chamorro-Atalaya ${ }^{1}(\varpi)$, Guillermo Morales-Romero ${ }^{2}$, Adrián Quispe-Andía ${ }^{2}$, \\ Nicéforo Trinidad-Loli ${ }^{2}$, Beatriz Caycho-Salas ${ }^{2}$, César León-Velarde ${ }^{3}$, \\ Sofía Gamarra-Mendoza ${ }^{4}$ \\ ${ }^{1}$ National Technological University of Lima Sur, Lima, Peru \\ ${ }^{2}$ Enrique Guzman y Valle National University of Education, Lima, Peru \\ ${ }^{3}$ Technological University of Peru, Lima, Peru \\ ${ }^{4}$ Saint Ignatius of Loyola University, Lima, Peru \\ ochamorro@untels.edu.pe
}

\begin{abstract}
The objective of this article is to know the satisfaction of students with online pedagogical support services, generated by the context of distance education due to the COVID-19 pandemic, which have been provided with various technological tools. During the development of the research, it was determined that there is a satisfaction with the pedagogical support of $61.2 \%$, being the indicators of health services and welfare university, those that present the highest satisfaction both with $62.3 \%$, on the other hand, are the indicators registrations and license plates, and psychopedagogical services those that present a greater dissatisfaction of 32.7 and 32.2, respectively. Although the pedagogical support provided by the university must continue to be improved, a slight improvement has been determined with the previous semester in which the adaptation of online services began, since dissatisfaction on the part of students decreased by $9.18 \%$.
\end{abstract}

Keywords-Distance education, student satisfaction, pedagogical support

\section{Introduction}

As indicated in [1], the compulsory social confinement caused by pandemic modified the way of life of human beings, however, social isolation did not mean an absolute stoppage of activities; on the contrary, the use of technological means increased, which gave rise to teleworking and tele-education. This is how it is pointed out in [2] that virtual learning drastically replaced face-to-face educational settings, so that the educational subject put aside social contact to come into direct contact with digital devices. Likewise, as indicated in [3], the pedagogical supports provided by universities such as psycho-pedagogical services and administrative-academic services, which were provided in person, drastically changed their policy and were redesigned to be provided virtually. 
As is known, in [4] it is indicated that, with technological progress, virtual education proposals seek to be revolutionary, with the interest of positively influencing not only the teaching-learning processes, but also the academic, administrative and psych pedagogical services offered by the universities. For this reason, in [5] it is indicated that we should make the most of the information and communication technologies (ICT), to eliminate the barriers that may exist in the use of virtually applied to education.

Taking into consideration, as described in [6], Peru was the first country in Latin America to declare quarantine upon detecting its first case of COVID-19, a state decision that affected all activities in the country. Generating, as indicated in [7], a strong emotional impact on the educational community and on society in general. In [8] it is pointed out that the closure of educational centers, the need for physical distancing, the loss of loved ones, the loss and shortage of work and the deprivation of conventional learning methods have generated stress, pressure and anxiety especially in students, teachers and their families.

For this reason, the study carried out in [9] indicates the great importance in this context of the psych pedagogical supports provided by universities, since these services are part of emotional education, which is a continuous and permanent educational process, which aims to promote human development, in order to train for life and in order to increase personal and social well-being.

Given this, it is essential to know the perception of students about the online pedagogical support services provided by universities. Even more so taking into consideration, as indicated in [10] that, under the face-to-face scenario, the pedagogical support services allowed the institutions to know the different realities of the student and of the institution itself, having as a positive factor how points out in [11] the communicational ability between the agent and the educational subject.

Given what has been described, the objective of this article is to know the satisfaction of students with online pedagogical support services, generated by the context of distance education due to the COVID-19 pandemic, taking into consideration that, for in order to provide these services, the university has gradually incorporated various online platforms.

\section{Investigation methodology}

\subsection{Research level}

The research level is descriptive, because it seeks to know the perception of students belonging to the 2020-B academic semester, about satisfaction towards online pedagogical support services, which have been offered through various technological tools acquired by the higher institution. Although the change in teaching-learning modality was carried out in the academic semester 2020-A, it should be noted that the adaptation period was too fast and unexpected, for this reason, the changes made regarding the use of virtual tools they were carried out in their entirety from the second academic semester, that is, in the 2020-B semester. 


\subsection{Study unit}

The participants that are part of this study are 705 students from the last three academic cycles, from the five university majors of the public university of Peru, which belong to the 2020-B academic semester; It is necessary to indicate that the selection of the participants, and the indicators that make up the pedagogical support variable were established and approved by resolution of the dean of the same university. Likewise, as part of the study we will observe the evolution in student satisfaction with pedagogical support services, for this we will take into account the survey conducted in the 2020-A semester, in which 695 students participated, with the same characteristics, already noted.

\subsection{Data Collection Technique and Instrument}

The data collection technique used is the survey; The pedagogical support variable is made up of four indicators, these are: psychopedagogical services, health services, welfare university, and registrations and license plates. The assessment was established in 4 levels, which were transformed using the Likert scale: Dissatisfied (1), Unsatisfied (2), Satisfied (3) and Very Satisfied (4).

\subsection{Validation of results of the data collection instrument}

The validation analysis of the results was performed with the Cronbach's alpha test, using the SPSS; When performing the data processing, it is determined that Cronbach's alpha is 0.934 ; and as indicated in [12], it can be interpreted that there is a high homogeneity in the response of all the indicators and respondents, since "values higher than 0.9 indicate great consistency". Likewise, the scales for each indicator that make up the pedagogical support variable reflect the internal consistency of the Likert scale used.

\section{Research results}

\subsection{Student satisfaction with online pedagogical support}

The results obtained in relation to the perception of the students belonging to the academic semester 2020-B, on the satisfaction towards the online pedagogical supports; reveal that with respect to the psychopedagogical services provided in this new context of distance education, that, of the total of 705 students, $11 \%$ indicated they were very satisfied, $49.4 \%$ indicated they were satisfied, $25.5 \%$ indicated they were unsatisfied and the $6.7 \%$ indicated that they were dissatisfied with the online psychopedagogical service, which was provided through a virtual platform where specialists provided emotional counseling to students.

Likewise, regarding the health services offered in this context of virtual normality, of the total of 705 students, $11.3 \%$ indicated that they were very satisfied, $51 \%$ indi- 
cated that they were satisfied, $23 \%$ indicated that they were unsatisfied, and $7.4 \%$ indicated that they found you dissatisfied with the online health service, which was provided through an application, in which specialists provided health advice to students.

Regarding the welfare university services offered in this virtual education normality, of the total of 705 students, $11.4 \%$ indicated they were very satisfied, $50.9 \%$ indicated they were satisfied, $23.3 \%$ indicated they were unsatisfied and $7.1 \%$ indicated that they found you dissatisfied with the welfare university service, which was provided through the web platform of the higher institution, in which the student could leave their case in writing, and the authorities were in charge of providing the corresponding help.

Finally, with respect to the registrations and license plates services offered in this distance learning environment, of the total of 705 students, $11.8 \%$ indicated they were very satisfied, $48.1 \%$ indicated they were satisfied, $24.2 \%$ indicated they were unsatisfied and the $8.5 \%$ indicated they were dissatisfied with the registrations and license plates service, which was provided through the web platform of the higher institution, in which the student with a username, password and previous training, granted by the university, could perform your tuition for the academic semester and all inquiries related to it.

According to the results, the indicators for registration and license plates, and psych pedagogical services are the ones that present the greatest dissatisfaction. Given this, the relationship between the satisfaction of both indicators will be specifically described, through the cross-table test through the SPSS, the results of which are shown in Table 1.

Table 1. Results of the cross-table test of the indicators with the highest dissatisfaction

\begin{tabular}{|c|c|c|c|c|c|c|}
\hline & \multicolumn{4}{|c|}{ Registrations and license plates } & \multirow[t]{2}{*}{ Total } \\
\hline & & Dissatisfied & Unsatisfied & Satisfied & Very Satisfied & \\
\hline \multirow{5}{*}{$\begin{array}{c}\text { Psychopedagogical } \\
\text { services }\end{array}$} & Dissatisfied & $84.3 \%$ & $7.8 \%$ & $5.9 \%$ & $2.0 \%$ & $100 \%$ \\
\hline & Unsatisfied & $5.7 \%$ & $66.5 \%$ & $26.3 \%$ & $1.5 \%$ & $100 \%$ \\
\hline & Satisfied & $2.4 \%$ & $13.3 \%$ & $79.5 \%$ & $4.8 \%$ & $100 \%$ \\
\hline & Very Satisfied & $2.4 \%$ & $1.2 \%$ & $15.5 \%$ & $81.0 \%$ & $100 \%$ \\
\hline & Total & $9.2 \%$ & $26.1 \%$ & $51.9 \%$ & $12.8 \%$ & $100 \%$ \\
\hline
\end{tabular}

From the most significant results in Table 1, it can be said that, of the total of 705 students, 129 of them agree that they are unsatisfied with both indicators (psychpedagogical support and registrations and license plates), likewise, 299 of them agree that they are satisfied with both. indicators, in addition 68 of them agree to be very satisfied with both indicators and only 43 students agree to be dissatisfied with both indicators.

In figure 1, the behavior model of the pedagogical support variable can be visualized, by modifying the perception of student satisfaction with respect to the online services provided by the university. 


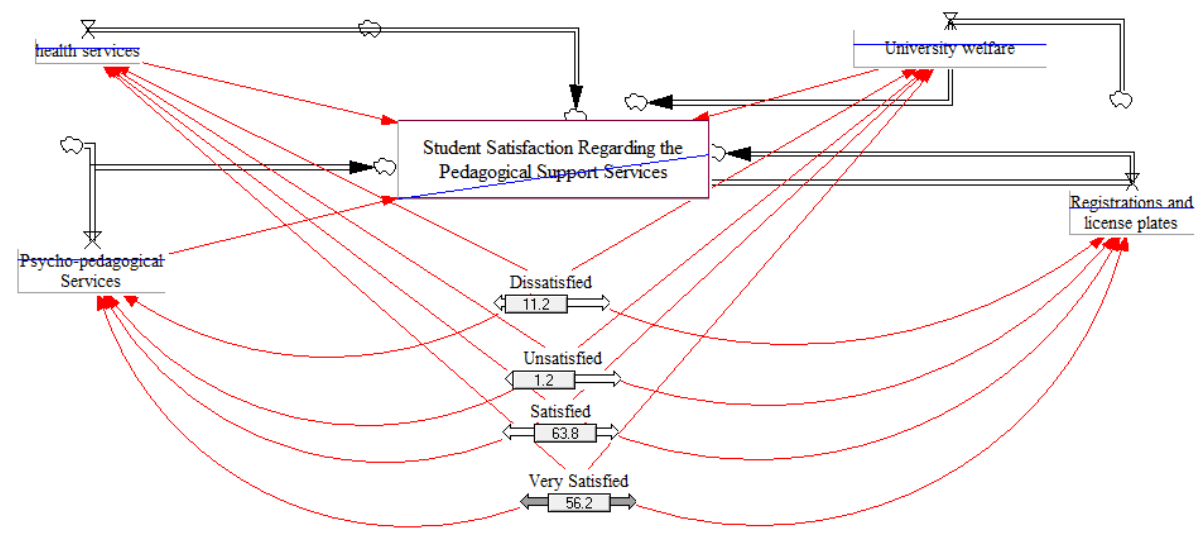

Fig. 1. Student satisfaction with pedagogical supports

\subsection{Evolution of student satisfaction in the distance education environment}

Figure 2 shows the results obtained in relation to the evolution of student satisfaction once the online pedagogical support services were implemented, which were adapted from the 2020-A academic semester.

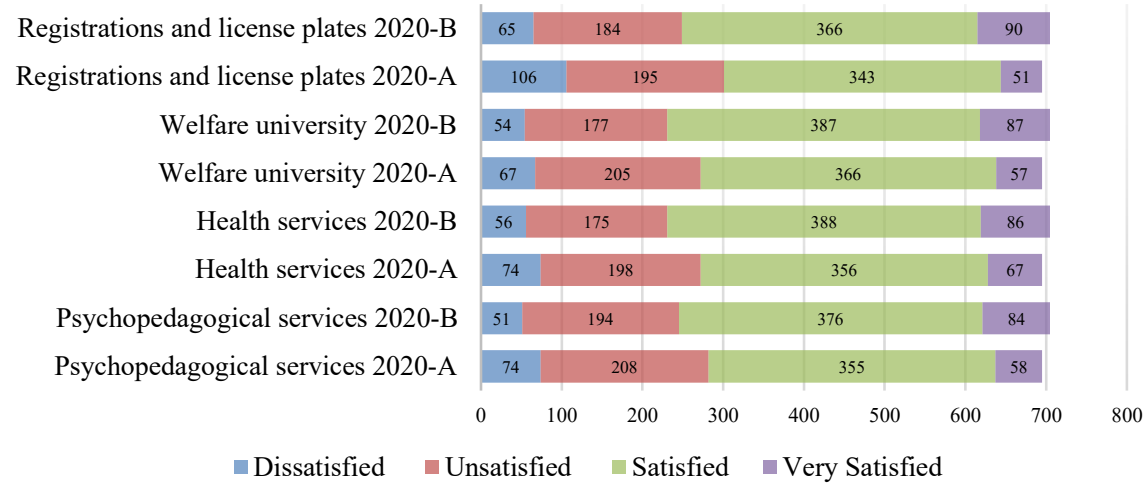

Fig. 2. Student satisfaction with pedagogical supports

As shown in figure 2, student satisfaction towards the online pedagogical support services provided in this new context of distance education has been improving, in the 2020-B semester, which is the second semester in which technological tools are being applied. As can be seen, with respect to psychpedagogical services, general dissatisfaction decreased by $8.8 \%$, also increasing student satisfaction by $4.6 \%$. Likewise, regarding health services, it is seen that dissatisfaction in general decreased by $8.6 \%$, also increasing student satisfaction by $1.3 \%$. Regarding the welfare university services, it is 
visualized that dissatisfaction in general decreased by $8.6 \%$, in turn increasing student satisfaction by $5.5 \%$.

Finally, with regard to the registration and license plates services offered in this distance learning environment, it can be seen that there is a greater variation, being also the indicator that presents a higher percentage of dissatisfaction in both academic semesters (2020-A and 2020-B), it can be seen that dissatisfaction in general decreased by $10.7 \%$, in turn increasing student satisfaction by $6.7 \%$, this regular percentage of dissatisfaction, may be because at the beginning of the adaptation of virtual teachinglearning, the university's online platforms did not respond adequately to the great demand of students, who for the first time jointly carried out the entire enrollment process online, in addition to the great congestion of the internet network that did not allow a correct connectivity of the users, thus generating an understandable malaise in the university community.

\section{$4 \quad$ Discussion of results}

The initial results of this research show that there is a student satisfaction with the pedagogical support of $61.2 \%$, this when seeing combined both satisfactory levels (very satisfied and satisfied), being the indicators university health and welfare services, those that present a higher satisfaction both with $62.3 \%$, on the other hand, it is the indicators of registrations and license plates, and psychopedagogical services that present a higher dissatisfaction of 32.7 and 32.2, respectively, this when seeing both unsatisfactory levels combined (dissatisfied and not very satisfied).

Regarding this, as indicated in the study by [6], 46\% of students are overwhelmed by the process of adapting to virtual classes and are deprived of the services provided by the university, either due to the virtualization of the classes or the context, also experiencing high levels of frustration. This is where psychopedagogical support services take on greater relevance, as stated in the study carried out in [13] despite the influence of the economic factor, the predominant reason for dissatisfaction, anguish or withdrawal (or the future possibility of doing so), which the students indicated was the wellbeing of their mental health.

Although the pedagogical support provided by the university should continue to be improved, in the second part of the results of this research, a slight improvement has been determined with the previous semester, that is, with the academic semester 2020A, in which The adaptation of online services began, due to the new normality of distance education, since dissatisfaction on the part of students decreased by $9.18 \%$, increasing satisfaction by $4.5 \%$. Regarding this, as indicated in [14], student satisfaction goes hand in hand with guaranteeing a good quality of the virtual services offered, being psychopedagogical supports and university welfare services, counseling that greatly benefit students distance education, in addition, as many studies highlight, the emotional aspect is closely related to the academic level.

In general, as indicated in the research of [7], the elements of distance education are the use of technology that in many cases is not applied and developed correctly, either due to lack of resources. or due to the lack of preparation for such an abrupt change in 
education, as has occurred in this virtual context. In addition, as indicated in [15], the use of technological resources must go beyond being only flexible means, the main participants, that is, students must find a particular dynamic with the relationships that generate this type of technology.

\section{Conclusions}

Distance education due to the health emergency, resoundingly change the scenarios of face-to-face teaching-learning to totally virtual scenarios, thereby generating the variation of the perception of each member of the educational community, and especially of the student which takes the main role in the educational process. However, the accelerated change to virtual reality reflects the precariousness in the design of policies for the digital age, which are perceived in the first place by students; the lack of digital devices, lack of connectivity, the limited use of technological tools, generates a variation in student satisfaction regarding this new normal. This becomes more relevant and becomes a challenge for the educational community when pedagogical support services have to be provided in this context with greater fixation and importance, even more so when virtual settings limit social contact, where it is more complex to recognize the emotions and physical affections of others.

The present research shows us that, although there is a favorable evolution, regarding student satisfaction with online pedagogical support, there are certain indicators that the authorities must take into account to continue improving them, such as the services of registrations and license plates and psychopedagogical services; with the improvement, a healthy environment would be obtained, in which a full learning is forged.

\section{References}

[1] F. Aguilar, "From face-to-face learning to virtual learning in pandemic times", Pedagogical Studies, vol. 46, no. 3, pp. 213-233, 2020.

[2] V. Rossado, D. Cárdenas-Salas, A. Cabrera and L. Coronel, "Virtual Reality and BIM Methodology as Teaching-Learning Improvement Tools for Sanitary Engineering Courses," International Journal of Emerging Technologies in Learning, vol. 16, no. 6, pp. 20-39, 2021. https://doi.org/10.3991/ijet.v16i06.13535

[3] D. Vlachopoulos, "Quality Teaching in Online Higher Education: The Perspectives of 250 Online Tutors on Technology and Pedagogy," International Journal of Emerging Technologies in Learning, vol. 16, no. 6, pp. 40-56, 2021. https://doi.org/10.3991/ijet. v16i06.20173

[4] V. Pando, "Teaching Trends in Virtual Education: An Interpretative Approach," Purposes and Representations, vol. 6, no. 1, pp. 463-505, 2018.

[5] B. Bahati, U. Fors, P. Hansen, J. Nouri and E. Mukama, "Measuring Learner Satisfaction with Formative e-Assessment Strategies," International Journal of Emerging Technologies in Learning, vol. 14, no. 7, pp. 246-247, 2019. https://doi.org/10.3991/ijet. v14i07.9120

[6] V. Gagliardi, "Educational challenges in times of pandemic," Question/Cuestión, vol. 1, no. 1, pp. 1-6, 2020. 
[7] L. Mendoza, "What the Pandemia Taught Us about E-learning," Latin American Journal of Educational Studies, vol. 50, no. 1, pp. 343-352, 2020.

[8] D. Hortiguela, V. Assín, V. Delgado and V. Abella, "COVID-19 and digital distance education: pre-confinement, confinement and post-confinement," Ibero-American Journal of Education a Distance, vol. 21, no. 1, pp. 9-25, 2021.

[9] A. Elizondo, J. Rodríguez and I. Rodríguez, "The importance of emotion in learning: Proposals to improve student motivation," University Pedagogy Notebook, vol. 15, no. 29, pp. 3-11, 2018.

[10] A. Dasso and I. Evaristo, "Learning outcomes analysis face-to-face and blended learning in two university coursesa," Eduction, vol. 29, no. 57, pp. 27-42, 2020.

[11] D. Vlachopoulos, "Quality Teaching in Online Higher Education: The Perspectives of 250 Online Tutors on Technology and Pedagogy," International Journal of Emerging Technologies in Learning, vol. 16, no. 6, pp. 40-56, 2021. https://doi.org/10.3991/ ijet.v16i06.20173

[12] J. Rodríguez-Rodríguez and M. Reguant-Álvarez, "Calculate the reliability of a questionnaire or scale using the SPSS: Cronbach's alpha coefficient," REIRE Revista d'Innovació i Recerca en Educació, vol. 13, no. 2, pp. 1-13, 2019. https://doi.org/10.1344/ $\underline{\text { reire2020.13.230048 }}$

[13] M. Lovón and S. Cisneros, "Impact of virtual classes on the university students in the context of COVID-19 quarantine: The case of the PUCP," Purposes and Representations, vol. 8, no. 3, pp. 1-15, 2020.

[14] J. Zambrano, "Prediction factors of student satisfaction in online courses," Ibero-American Journal of Distance Education, vol. 19, no. 2, pp. 217-235, 2016.

[15] E. Yong, N. Nagles, C. Mejía and C. Chaparro, "Evolution of distance higher education: challenges and opportunities for its management," Virtual Journal Universidad Católica del Norte, vol. 2, no. 50, pp. 81-105, 2017.

\section{Authors}

Omar Chamorro Atalaya, Electronic engineer, Renacyt-Concytec researcher, university professor in the associate category at the National Technological University of Lima Sur, Lima, Peru

Guillermo Morales Romero, Adrian Quispe Andía, Nicéforo Trinidad Loli and Beatriz Caycho Salas, Teachers at the Enrique Guzman y Valle National University of Education, Lima, Peru

Sofía Gamarra Mendoza, Teacher at the Saint Ignatius of Loyola University, Lima, Peru

César León Velarde, Teacher at the Saint Ignatius of Loyola University, Lima, Peru

Article submitted 2021-06-04. Resubmitted 2021-08-05. Final acceptance 2021-08-07. Final version published as submitted by the authors. 